Quim. Nova, Vol. 28, Suplemento, S44-S47, 2005

\title{
CONTRIBUIÇÃO À ORGANIZAÇÃO DA PESQUISA EM QUÍMICA E OS DESAFIOS DA INTERAÇÃo COM OUTRAS ÁREAS DO CONHECIMENTO
}

\author{
Oswaldo Luiz Alves \\ Instituto de Química, Universidade Estadual de Campinas, CP. 6154, 13084-971 Campinas - SP
}

\begin{abstract}
CONTRIBUTIONS TO THE CHEMICAL RESEARCH ORGANIZATION IN BRAZIL AND THE CHALLENGES ON THE INTERACTION WITH OTHER AREAS OF THE KNOWLEDGE. This article provides some aspects that allow making a current reading of the situation of the Brazilian Chemistry that permit us considerate it as a strategic area. They are still presented some initial proposals related to the organization of the research as well as to win the challenges of the relationship with the other areas of the knowledge.
\end{abstract}

Keywords: chemical research/Brazil; chemical research/proposals; chemical sciences observatory.

\section{INTRODUÇÃO}

Qualquer abordagem que se faça sobre a questão da pesquisa em Química no Brasil não pode deixar de considerar o impacto decisivo causado pelo PADCT - Programa de Apoio ao Desenvolvimento Científico e Tecnológico, através do subprograma de Química e Engenharia Química, cuja gestação teve início em $1982^{1}$.

Nunca é demais lembrar que o Programa de Química e Engenharia Química foi elaborado por um Grupo Técnico de Química e Engenharia, o qual reuniu cientistas, professores e profissionais da Química, vinculados a universidades, empresas e órgãos do governo, ligados a diferentes ministérios. Foi uma experiência absolutamente inovadora dado que, pela primeira vez, um grupo de pessoas, cobrindo amplo espectro de atividades, fazia um diagnóstico da área, definia estratégias e objetivos de ação, metas concretas a serem alcançadas, com cronogramas e recursos cuidadosamente dimensionados. O Programa foi também inovador no acompanhamento cuidadoso, fazendo sempre avaliações em vários níveis, que permitiram que o mesmo sofresse as correções de curso determinadas pelas circunstâncias, geralmente de ordem financeira.

Passados mais de 20 anos do início deste programa, seus efeitos positivos se fazem sentir na comunidade química brasileira. Praticamente quase todas as grandes lideranças científicas nacionais da Química, bem como muitas importantes facilidades laboratoriais concebidas - várias delas em pleno uso até hoje -, foram construídas durante a vigência deste Programa.

Tal situação fez com que a Química brasileira se firmasse, não só em nível nacional, mas também internacional, como altamente produtiva, participando ativamente do processo de aumento da produtividade científica brasileira, com uma contribuição de aproximadamente $13 \%$ dos trabalhos indexados.

A importância deste Programa é reconhecida por todos aqueles que estudam os diferentes aspectos da Química brasileira e, por isso mesmo (não poderia ser diferente), ele é citado várias vezes em diferentes pontos deste número de Química Nova.

\section{SINGULARIDADES DA QUÍMICA}

Um aspecto singular da Química é o fato de ser ela uma ciência na qual existe - para cada uma de suas disciplinas componentes -, um correspondente na atividade industrial.

*e-mail: oalves@iqm.unicamp.br
Tal aspecto faz com que a Química tenha um impacto sobremaneira significativo sobre a vida econômica do País, em razão do setor industrial: volume de produção, número de empregos gerados, geração de riquezas, etc., indo bem além disso, uma vez que ainda desempenha papel estratégico, dado alimentar, direta ou indiretamente, todas as outras atividades, inclusive as sociais ${ }^{2}$.

As características da Química e da pesquisa em química não param por aí. Segundo Bernier ${ }^{3}$, três pontos devem ser considerados. O primeiro é que a Química sabe e deve guardar suas raízes, ou seja, fazer novas moléculas, novos cristais, novos polímeros, vidros, ligas, etc. O segundo, que a Química pode e deve mudar de escala, ou seja, ir do estágio da molécula para o produto. Neste percurso, sabe-se, há um longo caminho, entretanto, a extrapolação, a formulação, a produção, levando em conta sobretudo seus modelos e conceitos são pontos importantes para que seu progresso se dê rapidamente. E, finalmente, o terceiro ponto, que mostra a implicação da química com outras áreas do conhecimento vizinhas, tais como materiais, através da física; medicamentos, por meio da biologia, e meio ambiente, via especialistas das ciências da terra.

É importante destacar que a indústria química brasileira ocupa a $9^{\text {a }}$. (nona) posição no Faturamento da Indústria Química Mundial, tomando-se como base o ano físcal de $2004^{4}$. Dentro de uma economia que contempla o desenvolvimento industrial como um dos fatores de progresso, a manutenção da competitividade dessas indústrias e seu desenvolvimento estão estreitamente ligados à ciência química e, sobretudo, ao sucesso de sua pesquisa fundamental: única capaz de garantir a geração e o progresso de novos conhecimentos da matéria, suas transformações e inovações. O grande desafio em nosso país é como criar uma sintonia entre academia e empresa, a ponto de tornarmos essa operação efetivamente sinergística. Certamente, algumas das respostas à questão ora colocada passam pela organização da pesquisa, sobretudo se considerarmos que o cenário é da pluridisciplinaridade, do relacionamento com outras áreas do conhecimento.

\section{ABRANGÊNCIA DA QUÍMICA}

As fronteiras da química se alargaram muito nos últimos 50 anos. Uma parte significativa da Química tem sua atividade ligada à síntese e processamento de materiais. O químico desenvolveu uma notável habilidade na construção de materiais a partir de seus componentes moleculares. Tal habilidade, associada à capacidade de criar funcionalidades nestes materiais, acabou por dar lugar a 
uma fronteira entre a química e as ciências dos materiais. Da mesma forma fronteiras foram criadas com a bioquímica e a biologia, na medida que a química adquiriu a capacidade de desenvolver materiais e dispositivos capazes de explorar processos biológicos, ou, ainda, construir materiais auto-organizados, "biologicamente inspirados" através de "blocos de construção". Avanços feitos nos últimos 20 anos, sobretudo em síntese e processamento de materiais, continuam a impactar sobremaneira campos emergentes, tais como a biotecnologia, a tecnologia da informação e, mais recentemente, a Nanotecnologia.

Tais colocações corroboram para que possamos asseverar que, sem sombra de dúvida, a atividade química em nosso país deve ser tratada como assunto estratégico. A força para fazermos tal assertiva encontra alicerces na consideração de vários fatores, entre eles: na existência de uma pesquisa acadêmica importante, de qualidade e diversificada no setor; contarmos com um parque industrial instalado, competente, com possibilidades e espaço para crescimento, e que, sobretudo, tem a percepção da inovação como fator de importância fundamental para o incremento dos negócios; termos disponíveis recursos naturais importantes (minerais e biológicos) e, finalmente, podermos contar com e nos valer da presença dos arcabouços da Política Industrial ${ }^{5}$ e da Lei de Inovação ${ }^{6}$.

Procuraremos, na seqüência, formular minimamente algumas propostas que, acreditamos, possam vir a contribuir para o aproveitamento destas oportunidades, ou mesmo aprofundar a discussão sobre o papel da Química em nosso país, enquanto ciência e indústria.

\section{ALGUMAS PROPOSTAS}

Começamos por apresentar, nos itens que seguem, algumas propostas ligadas à questão da organização da pesquisa no Brasil e ao desafio do relacionamento da Química com outras áreas do conhecimento:

\section{Avaliação de áreas de competência e "áreas cinza"}

Consideramos que a organização da pesquisa em Química passa pelo conhecimento/avaliação de nossos "pontos fortes" e de nossos "pontos fracos". É importante sabermos e, sobretudo, conhecermos a competência nacional - neste caso, acadêmica -, das áreas importantes do conhecimento químico. Salvo melhor juízo, um trabalho sistemático que procurasse conhecer esses parâmetros nunca foi feito em nosso país. Mesmo que tenhamos que trabalhar com as áreas tradicionais, em um primeiro momento, seria importante conhecermos e avaliarmos os contingentes de pesquisadores e as facilidades laboratoriais e instrumentais existentes para atividades nas áreas de Química Orgânica, Química Inorgânica, Química Analítica e Físico-Química. Num segundo momento, poderse-ia descer para as subespecialidades. De posse dessas informações, programas específicos poderiam ser induzidos, não somente procurando reforçar as "áreas cinza", mas também trabalhar a questão das fronteiras temáticas, dentro da própria Química, e com outras áreas do conhecimento. Esse trabalho teria como conseqüência a possibilidade da formatação de programas temáticos que, efetivamente, viessem a utilizar, de forma articulada, as "expertises" e facilidades nacionais, em programas de grande impacto científico e tecnológico, de interesse nacional, dentro da perspectiva de ciência e tecnologia para o desenvolvimento ${ }^{8}$.

\section{Da participação do setor produtivo nos projetos de pesquisa}

Nesse aspecto, demos um passo bastante importante quando, em editais temáticos de diferentes agências de financiamento, foi colocada a obrigatoriedade de um parceiro industrial, como forma de atrair o setor produtivo para uma participação efetiva no processo de desenvolvimento científico e tecnológico, tal como a nanotecnologia, por ex.. Apesar da importância das referidas parcerias, um passo ainda mais ousado é possível: fomentar programas (editais ou chamadas) dos quais possam participar conjuntamente várias empresas interessadas em um conhecimento básico ou aplicado focalizado, o qual seria compartilhado na forma de consórcio. Certamente a idéia não é nova, contudo, aportaria aos projetos uma quantidade de recursos bem maior, sem contar que a possibilidade da aproximação com o setor produtivo viabilizaria a transferência dos conhecimentos. Arranjos produtivos, setores industriais inteiros voltados para a exportação, cadeias produtivas identificadas poderiam, acreditamos, se beneficiar enormemente deste tipo de organização de pesquisa ${ }^{9}$.

\section{Construção de um projeto de Observatório de Informações Estratégicas em Química (OIEQ)}

Atitudes prospectivas para o planejamento e prospecção, seja para conferir base à formação do químico moderno, seja para a organização da pesquisa e visualização de suas novas oportunidades, e mesmo para avaliar possibilidades de mercado para as políticas do setor, passam pela necessidade de se contar com dados e informações validados, que permitam a construção de novos cenários para um futuro próximo, procurando tirar partido de diferenciais, perspectivando não apenas participação na geração de riqueza nacional, mas também no estabelecimento de bases para a sustentabilidade.

Considerando estes aspectos, não temos dúvida de que para a Química vir a dar um novo "salto de qualidade" - aquilo que poderia ser chamado de era pós-PADCT -, não só do ponto de vista acadêmico, mas aproveitando-se de uma importante base de conhecimento existente, do setor produtivo estabelecido e com vistas à inovação, seria importante a criação de um Observatório de Informações Estratégicas em Química (OIEQ), o qual pudesse ser, a um só tempo, um importante repositório de dados e informações sobre os avanços da atividade química, tanto do ponto de vista acadêmico quanto do ponto de vista industrial de ponta (sobretudo especialidades químicas), em nível mundial, e que também fosse capaz de oferecer subsídios para a elaboração de dossiês, relatórios prospectivos, etc., etc., sobre as diferentes áreas da Química.

Tais informações, em princípio, poderiam permitir a criação de ações induzidas e/ou "task-forces" de projetos, programas ou atividades com objetivos claramente identificados e valendo-se da "expertise" nacional. As colocações aqui feitas enfatizam a necessidade do desenvolvimento científico e industrial caminharem juntos, privilegiando temas e não disciplinas.

A presença de tal atividade, certamente terá seu escopo estendido se se considera que instituições como SBQ, ABIQUIM, ABIFINA, Academia Brasileira de Ciências, Agências de Fomento e vários ministérios, entre eles o da Indústria e Comércio, do Meio Ambiente, da Saúde, da Agricultura, entre outros, poderiam se beneficiar desta facilidade, abrindo largamente o escopo das interações com outras áreas do conhecimento.

Outro ponto importante a ser considerado nesta Proposta é o fato de se poder antecipar às rupturas tecnológicas que, por certo, acontecerão nos próximos anos, rupturas motivadas por novas tecnologias, entre elas a Nanotecnologia. Saber químico e atividade química nas empresas estarão fortemente imbricados nesta nova área, o que pode significar não somente novas oportunidades de pesquisa e desenvolvimento científico (em uma área de crescimen- 
to exponencial), como também novas oportunidades para a inovação, com conseqüente geração de produtos de elevado valor agregado, tudo isso fazendo parte de um cenário de altíssima competitividade e de convívio diuturno com mudanças de paradigmas ${ }^{10}$.

\section{Utilização das facilidades das tecnologias da informação}

Do ponto de vista da administração da pesquisa, o Brasil tem utilizado muitas e diferentes possibilidades oferecidas pela tecnologia da informação. Todavia, na pesquisa propriamente dita, acreditamos que a utilização das tecnologias de informação têm sido bastante acanhada.

Nesta perspectiva, uma proposta interessante seria a utilização da tecnologia da informação em um sentido mais amplo, ou seja: na operação remota de equipamentos ou no acompanhando da tomada de dados à longa distância, via internet. Tal tipo de utilização impactaria a organização da pesquisa, dada a possibilidade de interligar o país em termos das facilidades experimentais ligadas ao uso de equipamentos, sobretudo os de grande porte que, sendo muito custosos, não poderiam estar disponíveis em todos os pontos. Assim, acreditamos que poderiam ser maximizadas as facilidades instrumentais existentes no país, de modo muito mais abrangente e inclusivo.

Proposta semelhante foi feita quando da formulação do PPA de Nanotecnologia ${ }^{11}$. Sua reiteração é aqui feita - sob pena de sermos considerados rebarbativos -, por acreditarmos que a implementação de tal medida seria um avanço bastante significativo no que diz respeito à apropriação das facilidades, rapidez e segurança do uso das tecnologias da informação na organização da pesquisa, levando a uma característica de nossos dias, ou seja: a utilização mais e mais massiva da rede web, não só para envio de mensagens e troca de dados, mas também como ferramenta fundamental para melhoria do acesso às facilidades, e consequiente equilíbrio nas oportunidades de utilização de equipamentos de ponta, disponibilizados para a pesquisa nos grandes centros.

Neste caso, um exemplo talvez seja oportuno. Aquele que poderíamos colocar como mais próximo deste tipo de realização seria o uso da microscopia eletrônica, técnica fundamental para estudo de materiais, biologia e nanotecnologia. Existem no país poucas facilidades em microscopia eletrônica de alta resolução, de alto nível, de maneira que tais equipamentos poderiam ser compartilhados em nível nacional, através de protocolos bem estabelecidos, a partir de centros de competência.

\section{Começando a vencer os desafios da interação com outras áreas do conhecimento}

Nesta proposta, tratamos da questão da interação da Química com as outras áreas do conhecimento. Acreditamos que esta deveria ser uma ação induzida, ou seja, que a comunidade, através de suas Sociedades Científicas, poderia/deveria realizar congressos, reuniões anuais, workshops, colóquios, interdisciplinares e conjuntos, com diferentes áreas do conhecimento, tirando partido, efetivamente, das fronteiras e dos recobrimentos entre as diferentes áreas, por ex., eventos envolvendo químicos e físicos, químicos e biólogos, químicos e médicos, químicos e matemáticos, químicos e farmacólogos, etc. Deixar que tais interações aconteçam, quase que ao acaso, a exemplo das operações no seio das redes cooperativas de pesquisa, convenhamos, é muito pouco! Devemos, isto sim, partir para formas efetivas de interação, que permitam que diferentes comunidades possam ter oportunidade de compartilhar conhecimentos, permitindo, assim, não só a visualização, mas especial- mente o reconhecimento de que estas interações fazem emergir novas interfaces que não podem, de maneira conseqüente e consistente, ser mais tratadas por uma única especialidade. Trabalhar nessa direção, estamos certos, é uma boa oportunidade para que sejam criadas novas oportunidades para o futuro.

\section{CONSIDERAÇÕES FINAIS}

Alguns outros aspectos importantes devem ser considerados ao se tratar de tema tão multifacetado como o que aqui se apresenta. Não devemos perder de vista que a sustentação das ciências químicas e as possibilidades de crescimento da área são, em grande parte, determinadas pela qualidade da pesquisa fundamental, majoritariamente, em nosso país, realizada nas universidades e centros de pesquisa. Considerando que os recursos para o financiamento à pesquisa são comensuráveis, vis-à-vis às solicitações dos pesquisadores universitários e de centros de pesquisa, um cuidado especial deve ser tomado no sentido de que pesquisas realmente inovadoras, de alto risco e de alta qualidade não deixem de ser financiadas pelas agências de fomento.

A despeito do relacionamento entre as agências de financiamento e os pesquisadores, nestes últimos anos, ter melhorado substancialmente (editais, transparência, volume de recursos), algumas dificuldades podem ainda ser sentidas. Uma delas refere-se ao "time line" dos financiamentos que, via de regra, são muito longos, enquanto o ciclo do financiamento é mais curto, não obstante este último aspecto ter melhorado com os programas Institutos do Milênio, redes cooperativas de pesquisa, cuja duração tem sido de 3 anos. Resulta desta situação que parte importante do tempo é despendida na manutenção dos financiamentos, com prejuízo às atividades efetivas de pesquisa.

No caso da Química, pelas razões colocadas em parágrafos precedentes, fica clara a necessidade de pesquisas que tenham impacto sobre a sociedade e que garantam o seu próprio desenvolvimento. Hoje, em todos os discursos sobre esta questão, seja em países desenvolvidos ou emergentes, fala-se em problemas de pesquisa claramente identificados e focalizados, problemas que são vistos como importantes pela população, até para que sejam "capturados" e "apropriados" pela sua imaginação e trazidos para seu dia-a-dia.

Finalmente, nossa experiência pessoal faz-nos crer que, de maneira geral, uma Química forte - pluri e muldisciplinar -, pode levar a um melhor entendimento da ciência e da tecnologia, o que, no limite, permitirá formar uma nova geração de profissionais, com elevado senso analítico e crítico.

\section{REFERÊNCIAS E NOTAS}

1. O período de execução do PADCT foi de radical mudança da Química brasileira: fomentou um surto de grande crescimento, qualitativo e quantitativo, das atividades científicas, tecnológicas e de ensino-educação em química. Terminada a primeira fase do PADCT, o sucesso do subprograma de Química e Engenharia Química era tal, que este foi mantido como o principal subprograma do PADCT, na sua segunda fase. A esta altura, os impactos eram muitos e nítidos: nos laboratórios de ensino e de pesquisa, nas bibliotecas, nas plantas multipropósito de desenvolvimento e produção de produtos e de processos e em centros de desenvolvimento tecnológico. Houve, também, um impacto importante sobre o CNPq, que se mostrou capaz de implementar administrativamente e acompanhar projetos de centenas de milhares de dólares, rompendo com uma tradição de só responsabilizar-se por projetos pequenos - no valor e nos propósitos.

2. As colocações feitas ganham maior força argumentativa se considerarmos o faturamento global da Indústria Química nos últimos anos (em bilhões de dólares): $2000:$ 43,6; 2001: 38,8; 2002: 37,3; 2003: 45,5 e 2004: 59,4. Segundo a ABIQUIM - Associação Brasileira da Indústria Química, a 
indústria química tem papel de destaque no desenvolvimento das diversas atividades econômicas do País, participando ativamente de quase todas as cadeias e complexos industriais, inclusive serviços e agricultura. No caso brasileiro, de acordo com o último dado disponível, relativo ao ano de 2003 , a participação da química no PIB total foi de 3,7\% . A título comparativo, nos Estados Unidos (maior indústria química do mundo), a participação no PIB é de cerca de $2 \%$. Levando em consideração a matriz industrial do Brasil, ainda segundo dados do IBGE, o setor químico ocupa a segunda posição, com quase $12 \%$ do PIB da indústria de transformação, atrás apenas do setor de alimentos e bebidas, que tem cerca de $17 \%$ do total. Fonte: http://www.abiquim.org.br

3. Estas observações foram feitas por Jean-Claude Bernier, então Diretor do Departamento de Ciências Químicas do CNRS (França), no texto "Chimie, Quand Tu Nous Tiens!", publicado no site do http://www.cnrs.fr, acessado em 2003.

4. Fonte Abiquin: http://www.abiquim.org.br, acessado em Outubro 2005.

5. Para conhecer mais sobre a Política Industrial veja: http:// www.desenvolvimento.gov.br/arquivo/ascom/apresentacoes/Diretrizes.pdf

6. A Lei de Inovação foi assinada pelo presidente Luiz Inácio Lula da Silva no dia 11 de outubro de 2005. O decreto, de número 5.563, foi publicado no dia 13, no Diário Oficial da União. http://lqes.iqm.unicamp.br/images/ lqes_empauta_novidades_661_decreto_lei_inovacao.pdf

7. Entendemos neste texto por "áreas cinza", áreas da Química nas quais as atividades estão muito difusas, pouco organizadas, ou mesmo, áreas consideradas importantes para o desenvolvimento da química e da indústria que ainda são muito pouco disseminadas em nosso meio.

8. Estudo com estas características foi realizado pelo Centro de Gestão em Estudos Estratégicos, CGEE para a área de Nanotecnologia em 2004 e 2005. Tais estudos podem ser complementados pelo uso das técnicas Delphi que permitiria, além do conhecimento da capacitação nacional na área, consensos sobre a importância, relevância e oportunidade de se estudar diferentes temas.
9. Programa interessante que abordou a pesquisa dentro desta perspectiva foi o Programa Genona-FAPESP, no estudo da bactéria Xylella fastidiosa, nome científico da praga do amarelinho que trazia grande prejuízo aos laranjais paulistas. Neste caso houve a participação da Fundecitrus (Fundo Paulista de Defesa da Citricultura), mantido por produtores de laranja e indústrias de suco. Conheça mais sobre este case em: http:// watson.fapesp.br/Imprensa/usp02.htm

10. Avanços nas tecnologias bio/nano/materiais/info hoje se combinam para tornar possíveis dispositivos e sistemas com efeitos globais sobre indivíduos, saúde pública e segurança; sistemas políticos, econômicos e sociais; negócios e comércio. A emergente Revolução Tecnológica, juntamente com o processo de globalização, capitaneada pela tecnologia da informação e pelo aumento da sua capacidade de transporte, se por um lado introduz o aumento da expectativa de vida, prosperidade econômica e qualidade de vida, por outro, introduz importantes problemas no que diz respeito à privacidade e às questões éticas. Muitos autores têm colocado que o passo acelerado que as mudanças tecnológicas vêm tendo podem levar a um aumento cada vez maior do "gap" entre países ricos e pobres, países desenvolvidos e em vias de desenvolvimento. Entretanto, o aumento da conectividade global com a revolução tecnológica pode ele próprio se constituir em um veículo para melhorar a educação e as capacidades técnicas que permitam que países pobres e regiões menos desenvolvidas do mundo possam também se favoreçer dos desenvolvimentos tecnológicos via o "cottage industrial" do século 21. (P.S. Anton, R. Silberglitt e J.Schneider em "The Global Technology Revolution", Rand, 2001 - http:/ /www.rand.org

11. Para maiores detalhes consulte o documento "Desenvolvimento da Nanociência e Nanotecnologia", produzido pelo Grupo de Trabalho criado pela portaria MCT no. 252, que serviu de base para o Programa de Desenvolvimento da Nanociência e Nanotecnologia do PPA (Plano Plurianual) 2004-2007. http:// www.mct.gov.br/Temas/Nano/prog_nanotec.pdf 